\title{
Successful Reversal of Acute Lung Injury using Placenta-Derived Decidual Stromal Cells
}

Olle Ringdén ${ }^{1 *}$, Martin Solders', Tom Erkers', Silvia Nava', Pia Molldén', Malin Hultcrantz², Helen Kaipe ${ }^{1 *}$ and Jonas Mattsson ${ }^{1 \#}$

${ }^{1}$ Division of Therapeutic Immunology and Center for Allogeneic Stem Cell Transplantation, Karolinska University Hospital Huddinge, Stockholm, Sweden ${ }^{2}$ Department of Hematology, Karolinska Institutet, Karolinska University Hospital Huddinge, Stockholm, Sweden

\#Contributed equally

\begin{abstract}
Introduction: The placenta protects the fetus from the mother's immune system. We have shown that placentaderived decidual stromal cells (DSCs) are immunosuppressive and can cure graft-versus-host disease. Acute lung injury (ALI) is life-threatening and has no specific therapy.

Materials and methods: A 33-year-old man with chronic myeloid leukemia developed ALI after allogeneic hematopoietic cell transplantation and sepsis. Blood culture yield $\alpha$-streptococci. He became hypoxic and chest radiography suggested acute respiratory distress syndrome. He required $15 \mathrm{~L} / \mathrm{min}$ oxygen by mask.

Result: After infusion of $1 \times 10^{6} \mathrm{DSCs} / \mathrm{kg}$ on day +11 after transplantation, oxygen saturation instantly increased from $92 \%$ to $98 \%$ and stabilized. The requirement for oxygen decreased and was discontinued on day +16 . Chest radiography improved and normalized. Elevated systemic levels of proinflammatory cytokines/chemokines G-CSF, IL-6, IL-8, MCP-1, and TNF- $\alpha$ decreased. The patient was discharged on day +22 with normal chest radiography. He is alive and well nine months after transplant.
\end{abstract}

Conclusion: Stromal cells may be useful for ALI and deserves to be further explored for this indication.

Keywords: Acute lung injury; Acute respiratory distress syndrome; Sepsis; Allogeneic hematopoietic cell transplantation; Leukemia; Immunotherapy; Decidual stromal cells

\section{Introduction}

Acute lung injury (ALI)/acute respiratory distress syndrome (ARDS) is the cause of death of approximately 75,000 patients in the United States annually [1]. The syndrome consists of acute hypoxic respiratory failure with bilateral pulmonary infiltrates associated with sepsis, pneumonia, shock following severe trauma, or aspiration of gastric contents $[2,3]$. ALI is characterized by rapid alveolar injury, inflammation, cytokine induction, and neutrophil accumulation. This causes protein-rich pulmonary edema, which leads to severe hypoxemia and impaired carbon dioxide excretion. The term ARDS is used if the patient's $\mathrm{PaO}_{2} / \mathrm{FiO}_{2}$ ratio is less than 200, but ALI could be applied to a wider spectrum of lung disorders [4]. Mechanical ventilatory support was not considered to be a requirement by the American-European Consensus Conference on ARDS when defining ALI or ARDS [4]. ALI/ARDS has a substantial impact on public health in the USA, being responsible for $3.6 \times 10^{6}$ hospital days per year, and there are no efficient treatments $[1,3]$.

Mesenchymal stromal cells (MSCs) have a strong anti-inflammatory effect and have been widely used in regenerative medicine for their multipotent differentiation and immunosuppressive capacities $[5,6]$. We were the first to use MSCs for treatment of life-threatening acute graft-versus-host disease (GVHD), with complete resolution of all symptoms in some patients and no effect in others $[7,8]$. Long-term survival in these patients was less encouraging and alternate therapies were sought after [9]. The fetus is protected from the mother's immune system by the placenta and the fetal membranes. The decidua, which is a membrane of maternal origin, plays an important role in feto-maternal tolerance [10]. We have found that decidual stromal cells (DSCs) are immunosuppressive and may cure acute GVHD $[11,12]$. We switched to DSCs for clinical use because they have a more reproducible immunomodulatory effect than MSCs, they are easier to obtain, and they have better expansion capacity than MSCs $[11,12]$.
Preclinical studies have suggested that MSCs may be of value in treating ALI [13-16]. We used DSCs to treat a 33-year-old man-an allogeneic hematopoietic cell transplantation (AHCT) recipient-for ALI/ARDS because this is an often lethal complication after AHCT [17].

\section{Methods}

\section{Patient}

A 33-year-old man with chronic myeloid leukemia (CML) underwent AHCT with a graft from an HLA-identical unrelated donor due to unresponsiveness to nilotinib and a T315i mutation. The treatment of choice for patients with CML is thymidine kinase inhibitors, but patients with this mutation do not respond to this treatment and are referred for AHCT. He received conditioning with busulfan $(16 \mathrm{mg} / \mathrm{kg})$ orally, given over four days and adjusted to pharmacokinetics, and $120 \mathrm{mg} / \mathrm{kg}$ cyclophosphamide [18]. Immunosuppression was antithymocyte globulin, cyclosporine, and four doses of methotrexate $[19,20]$. The transplantation procedure and supportive care have already been described in detail [19].

\section{Decidual stromal cells}

Human term placentas were obtained from healthy mothers

${ }^{*}$ Corresponding author: Olle Ringdén, MD, PhD, Professor of Transplantation Immunology, Karolinska Institutet, Division of Therapeutic Immunology, Karolinska University Hospital Huddinge, F79, SE-141 86 Stockholm, Sweden, Tel: +46 8585 82672; Fax: +46 8 7466699; E-mail: Olle.Ringden@ki.se

Received July 17, 2014; Accepted November 16, 2014; Published November 18,2014

Citation: Ringdén O, Solders M, Erkers T, Nava S, Molldén P, et al. (2014) Successful Reversal of Acute Lung Injury using Placenta-Derived Decidual Stromal Cells. J Stem Cell Res Ther 4: 244. doi:10.4172/2157-7633.1000244

Copyright: (c) 2014 Ringdén O, et al. This is an open-access article distributed under the terms of the Creative Commons Attribution License, which permits unrestricted use, distribution, and reproduction in any medium, provided the original author and source are credited. 
during elective caesarian-section births, after obtaining informed consent. Ethical approval to culture DSCs from placentas, and also to use them clinically for GVHD, inflammation and toxicity after AHCT, was obtained from the Institutional Ethical Review Board of Karolinska Institutet (2009/4-18-31/4,2010/452-31/4). The procedure for isolation, expansion, and freeze-thawing of DSCs using good manufacturing practice has been published [12]. Viability after thawing is above $90 \%$. DSCs were characterized by flow cytometry and they were positive for CD29, CD44, CD73, CD90, and CD105 but negative for hematopoietic markers CD45, CD14, and CD34 and for endothelial and epithelial markers CD31 and EpCAM-1, respectively. DSCs showed some adipogenic differentiation but poor capacity to differentiate into osteoblasts and chondrocytes when grown in induction media [12,21]. DSCs inhibited alloantigen-stimulated lymphocytes in vitro $[11,12]$.

\section{Cytokine analysis}

Blood samples were collected before and at several time points after DSC infusion. Cytokines were measured in patient serum by Bio-Plex Human Cytokine 27-Plex assay (Bio-Rad, CA).

\section{Results}

\section{Patient outcome}

After myeloablative conditioning and AHCT, the patients are neutropenic for about two weeks. During the neutropenic phase, most patients develop fever and around half of them have sepsis. On day +8 after AHCT, during neutropenia, the patient developed fever $\left(40^{\circ} \mathrm{C}\right)$ and was treated with high-dose piperacillin/tazobactam (Figures 1A-C). Chest radiography was unchanged compared to before transplantation. On day +9 , the high fever continued with a maximum pulse of $155 / \mathrm{min}$. Blood pressure was $120 / 60 \mathrm{mmHg}$. Blood culture yielded $\alpha$-streptococci. Due to sepsis, hemoglobin decreased from 100 to $60 \mathrm{~g} / \mathrm{L}$. Two units of erythrocytes and one unit of platelets were given. Weight increased from $77 \mathrm{~kg}$ to $82 \mathrm{~kg}$, most likely due to pulmonary edema. There was no swelling and no ascites. His serum creatinine and phase reactive protein increased. On the following day $(+10)$, he became short of breath and oxygen saturation showed $92 \%$ (Figures $2 \mathrm{~A}$ and $2 \mathrm{~B}$ ). Chest radiography suggested ARDS (Figure 3A). Oxygen supply, which had been 2-4 L/min during the previous day, was now increased to $15 \mathrm{~L} / \mathrm{min}$ (Figure 2B). Albumin had decreased from $29 \mathrm{~g} / \mathrm{L}$ to $19 \mathrm{~g} / \mathrm{L}$ (Figure 1B). Over $48 \mathrm{~h}$, he was given $100 \mathrm{~mL}$ $(20 \mathrm{~g})$ albumin six times and a total dose of $250 \mathrm{mg}$ furosemide

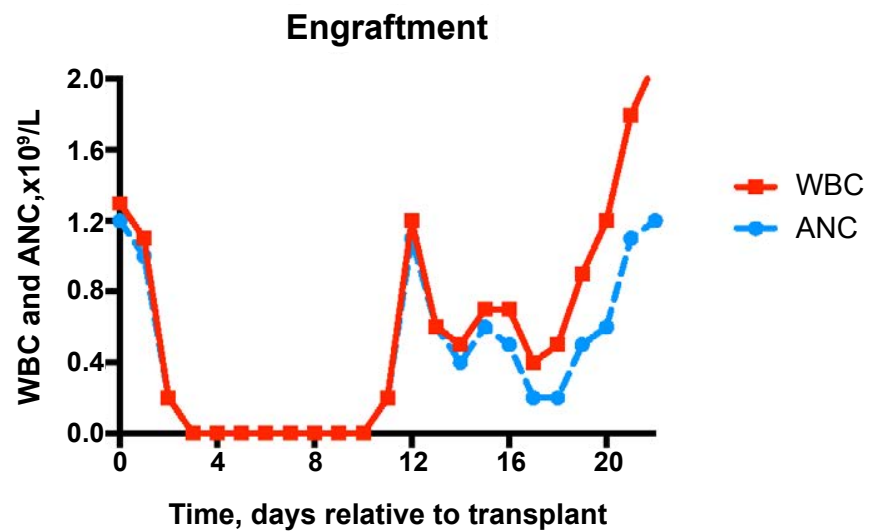

Figure 1A: Total white blood cells (WBC) $\times 10^{9} / \mathrm{L}$ and absolute neutrophil count (ANC) $\times 10^{9} / \mathrm{L}$. This shows neutropenia after conditioning and donor cell engraftment and increase from day +11 after transplantation.

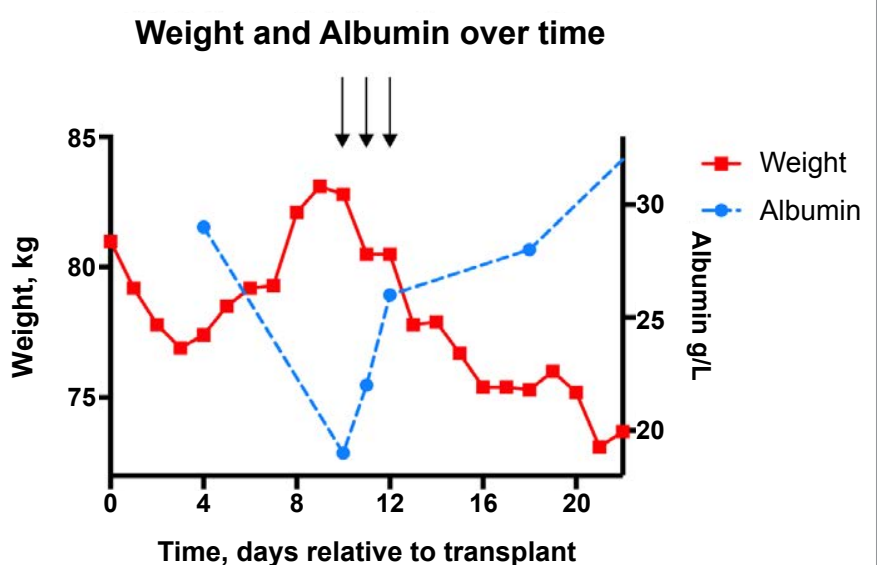

Figure 1B: Weight $(\mathrm{kg})$ and albumin $(\mathrm{g} / \mathrm{L})$. Arrows indicate albumin and furosemide infusions. Weight increased due to ALI/ARDS with pulmonary edema and low serum albumin. After treatment with albumin and diuretics, the weight and fluid overload in the lungs was stabilized. After DSCs were given, weight and albumin normalized.

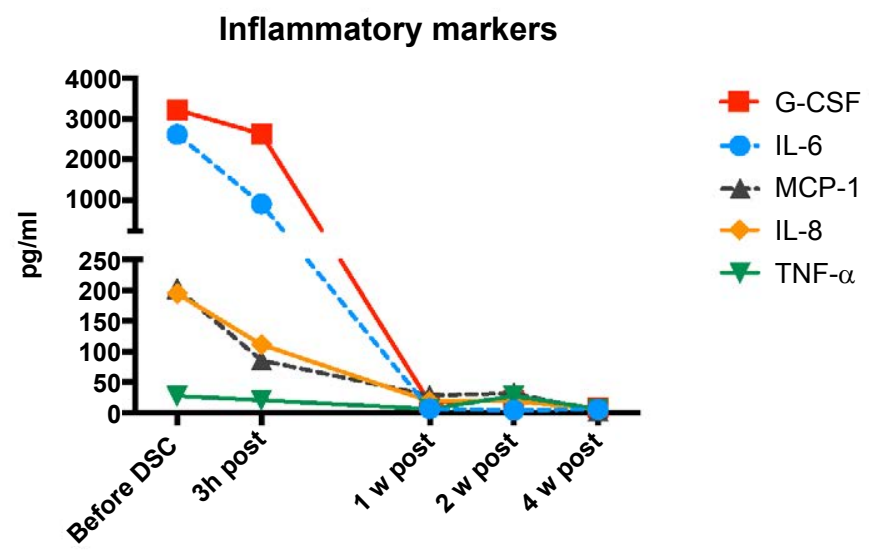

Figure 1C: Levels of G-CSF, IL-6, IL-8, MCP-1, and TNF- $\alpha$ in serum before infusion of decidual stromal cells and after three hours, one week, two weeks and four weeks.

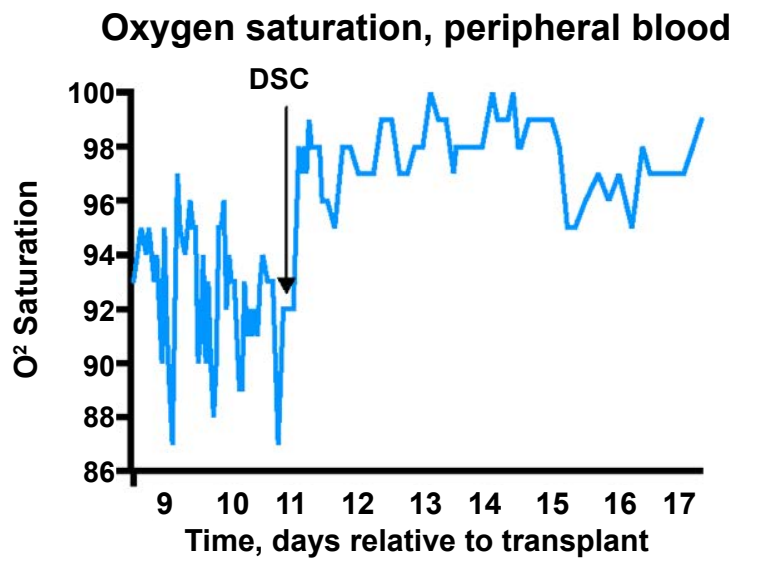

Figure 2A: Oxygen saturation and oxygen supply. A) Oxygen saturation by pulse oximetry (\%). The $y$-axis shows days after transplantation. The arrow shows when decidual stromal cells (DSCs) were given and the prompt increase in saturation. 


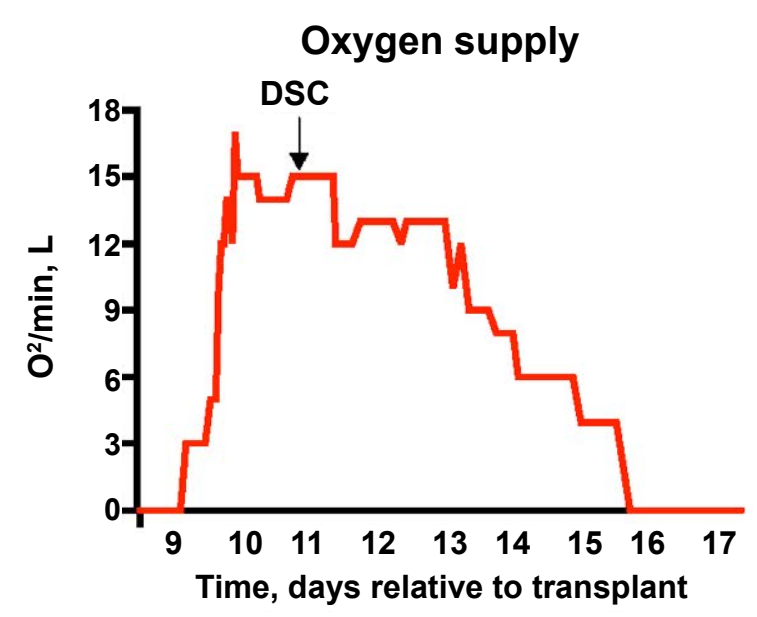

Figure 2B: Oxygen supply (L/min) given to the patient by mask on various days after transplantation. After DSCs were given (arrow), the oxygen supply was reduced and discontinued five days later.

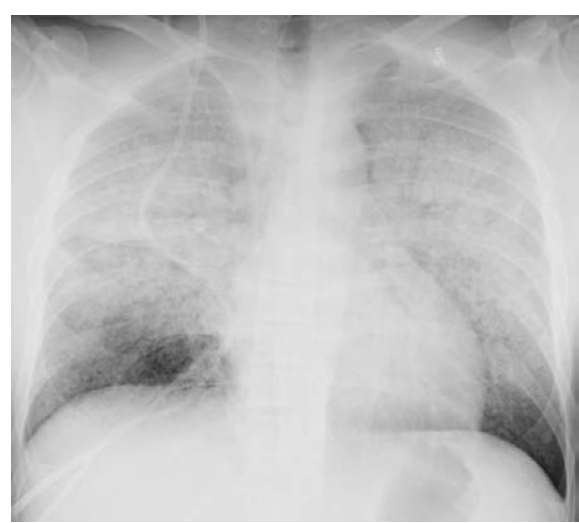

Figure 3A: Radiography findings. A) Chest radiography on day +10 , suggesting acute respiratory distress syndrome.

intravenously, divided into five doses. This was given to mobilize fluid and decrease the pulmonary edema. Urinary output was $4.9 \mathrm{~L}$ on day +10 and $4.8 \mathrm{~L}$ on day +11 . Weight was stable at around $80 \mathrm{~kg}$ and central venous pressure (CVP) ranged from $+1.5 \mathrm{mmHg}$ to $+8 \mathrm{mmHg}$. On day +11 , chest radiography was slightly worse, compared to the day before (Figure 3B). He had signs of engraftment with white blood cells (WBCs) and absolute neutrophil count (ANC) of $0.2 \times 10^{9} / \mathrm{L}$ (Figure 1A). Bilirubin increased from $13 \mathrm{mmol} / \mathrm{L}$ to $45 \mathrm{mmol} / \mathrm{L}$. Betametason, $6 \mathrm{mg}$ i.v., was given once daily, although not proven to be effective [3]. By this time he was completely exhausted.

On a compassionate basis and after obtaining written informed consent, $1 \times 10^{6} \mathrm{DSCs} / \mathrm{kg}$ were infused during five minutes. Before infusion, oxygen saturation in blood was $92 \%$ and within minutes after infusion it increased to $98 \%$ (Figure $2 \mathrm{~A}$ ). Then oxygen saturation stabilized; the requirement for oxygen decreased and it was discontinued on day +16 (Figure $2 \mathrm{~B}$ ). Chest radiography improved (Figure 3C).

On day +22 , the patient was discharged from hospital with normal chest radiography (Figure 3D). Weight was $74 \mathrm{~kg}$, hemoglobin $118 \mathrm{~g} / \mathrm{L}$ (normal value $134-145$ ), WBCs $2.1 \times 10^{9} / \mathrm{L}(3.5-8.8)$, ANC $1.2 \times 10^{9} / \mathrm{L}$ (1.6-7.5), platelets $88 \times 10^{9} / \mathrm{L}(145-348)$, and serum creatinine $56 \mu \mathrm{mol} / \mathrm{L}$ $(<100)$ (Figure 1A). His laboratory values are satisfactory for being three weeks after AHCT, although blood counts are lower than in the normal population. The patient went home, is still well, and is being followed at the outpatient clinic now nine months after AHCT.

\section{Cytokine and chemokine analysis}

Elevated systemic levels of proinflammatory cytokines/ chemokines, granulocyte colony-stimulating factor (G-CSF), IL-6, IL8 , and MCP-1 decreased already $3 \mathrm{~h}$ after treatment with DSCs (Figure 1C). The concentrations continued to drop at 1 week after infusion,

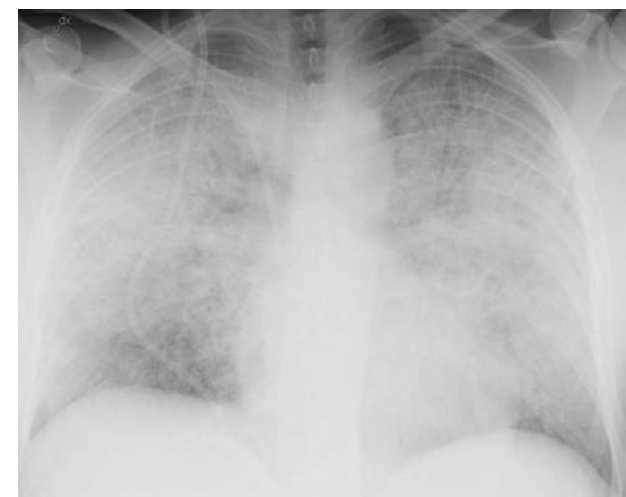

Figure 3B: Chest radiography on day +11 after transplantation with neutrophil recovery and before decidual stromal cells were infused. The radiography is slightly worse than on day +10

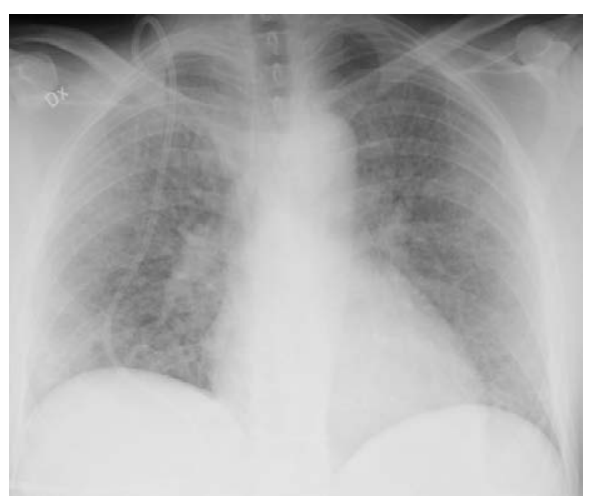

Figure 3C: Chest radiography three days after infusion of DSCs on days +14 after transplantation; it is now improved.

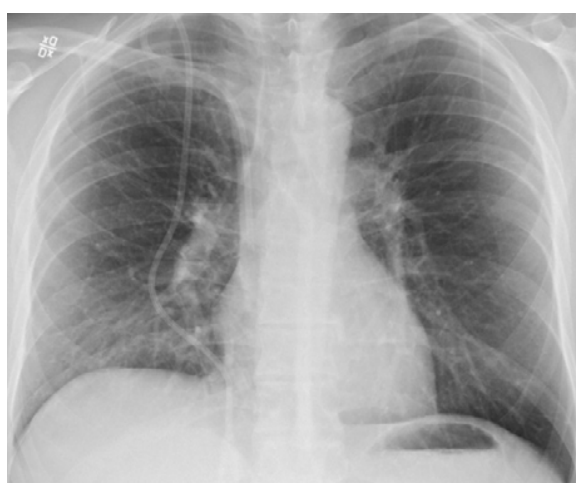

Figure 3D: Chest radiography on day +22 after transplantation at the time of discharge; it is now normal. 
and remained low thereafter. The level of TNF- $\alpha$ was only marginally increased before infusion with DSCs, probably due to the low monocyte count, but it showed the same pattern as the other cytokines and gradually decreased. The levels of IL-10 remained low throughout the monitoring time.

\section{Discussion}

There was a significant clinical response to DSCs in this case, with improved oxygen saturation, reduced need for oxygen, and improvement in chest radiography. Proinflammatory cytokines are increased during sepsis and ALI/ARDS [3]. The high levels of G-CSF, IL-6, IL-8, and MCP-1 in this patient decreased after infusion with DSCs (Figure 1C). TNF- $\alpha$ also decreased. In ALI/ARDS, alveolar macrophages and epithelial cells secrete these cytokines, which act locally to stimulate chemotaxis and activate neutrophils [3]. After neutrophil engraftment, it was feared that activated neutrophils would release oxidants, proteases, leukotrienes, and other proinflammatory molecules, which would be expected to worsen lung damage and pulmonary function in this patient. The DSCs, which are strongly antiinflammatory and induce immune modulation, probably dampened this effect.

The positive effects of MSCs on various types of lung injury and sepsis have been demonstrated in several animal models $[13,14,16]$. In addition, it has been shown that amniotic epithelial cells isolated from the placenta can abrogate lung fibrosis and enhanced alveolar repair in a murine model [22]. MSCs have been shown to dampen lung injury by E. coli endotoxin in an ex vivo perfused human lung [15]. In a mouse model, where MSCs attenuated sepsis, the effect was dependent on MSC-derived prostaglandin $\mathrm{E}_{2}$, which reprogrammed macrophages in septic lung to become potent producers of anti-inflammatory IL-10 [16]. We did not see any change in IL-10 in the serum of this patient, which contrasts with some animal studies $[3,14,15]$. In line with these experimental models, we have previously found that DSCs induce IL-10 production from peripheral blood mononuclear cells in vitro [11]. The unchanged levels of IL-10 in this patient may be explained by species differences or simply by the absence of enough myeloid cells at the time of DSC infusion. DSCs require cell contact to be immunosuppressive, an effect that is induced by indoleamine2,3-dioxygenase, prostaglandin $\mathrm{E}_{2}$, interferon- $\gamma$, and PD-L1 [21]. The immunomodulatory and anti-inflammatory effects by DSCs seem slightly different from those induced by MSCs. Further research is therefore needed to explore the exact mechanism how DSCs influence ALI. The mechanisms how DSCs worked in this case are that they first home to the lung in large numbers and probably had a strong local effect on the cytokine-induced ALI. The effect on cytokines was systemic and measurable in blood.

We used a fluid-conservative strategy, which has been proven to be effective in ARDS, in contrast to pharmacological treatments $[3,23]$. We also wanted to avoid ventilator assistance, because this may worsen lung injury in patients who have undergone AHCT. This happens despite the fact that a lung-protective ventilatory strategy introduced in recent years, using lower tidal volumes and lower airway pressure, is protective in ALI-in contrast to previously used traditional tidal volumes [3].

When using MSCs or DSCs to treat steroid-refractory acute GVHD, a proportion of the patients respond $[8,12]$. In a similar way, it is probable that not all patients with ALI/ARDS would benefit from stromal cell therapy. Three years ago, we treated a 13 -year-old boy with white lungs (appearing after granulocyte transfusions given due to prolonged neutropenia after AHCT) with $1 \times 10^{6} \mathrm{MSCs} / \mathrm{kg}$. He subsequently required ventilatory assistance and died of massive aspergillosis pneumonia. A long-term follow-up study found that many patients with acute GVHD that was treated with MSCs died from invasive fungal infection [9]. Thus, antifungals should be considered in patients treated with stromal cells, especially if they have had acute GVHD.

DSCs, like MSCs, first home to the lung after i.v. infusion and have potent anti-inflammatory effects [24]. In addition, MSCs home to damaged tissue [25]. Thus, they may be useful for ALI/ARDS Stromal cells-MSCs and DSCs-have no acute toxic side effects $[8,12,25]$. We have now treated 55 patients with 116 infusions of DSCs and have not seen any acute side-effects (Ringdén et al, unpublished data). Bone marrow-derived MSCs have been used in more than 2,000 patients in hundreds of clinical trials without any acute toxicity reported $[26,27]$. There is some concern with the report of pulmonary embolism following infusion of adipose-derived MSCs [28]. As there is no effective therapy for ALI, there is little to lose and much to gain by treating patients with stromal cells.

In the USA, the Osiris Company has a patent on MSCs for a large number of clinical indications. This makes it difficult to use MSCs expanded in research laboratories for clinical studies in the USA. DSCs are a different type of cell, with different features and a slightly different mechanism of action [21]. The use of DSCs affords the possibility of performing clinical stromal cell research at US institutions. If one cell type is more effective than the other remains to be elucidated. There is a great interest and potential of using stromal cells for lung disorders $[3,26,27,29]$.

A small prospective randomized placebo-controlled study using adipose-derived MSCs including 12 patients with ARDS was reported [30]. There was no difference in clinical outcome or effect on biomarkers between the two groups. Sixty-two patients were included in a placebo-controlled randomized study of MSCs for chronic obstructive lung disease [31]. The only positive effect was a significant decrease of C-reactive protein in the MSC group with elevated levels prior to infusion. Otherwise, there were no differences between the MSC group and the placebo group regarding outcome parameters. The two randomized studies showed that systemic MSC administration was safe and there were no side-effects seen [30,31]. These studies provide the basis for subsequent cell therapy investigations and further optimization of this strategy is required. If DSCs have any advantages compared to MSCs in the treatment of lung diseases remains to be elucidated.

The case described here is encouraging and calls for further pilot studies and subsequently prospective, controlled studies with DSCs or MSCs for the treatment of ALI/ARDS.

\section{Acknowledgements}

This paper is dedicated to the memory of Professor Carl-Gustav Groth, MD $\mathrm{PhD}$, who was a pioneering transplant surgeon and an inspiring mentor. We thank the Staff at the Center for Allogeneic Stem Cell Transplantation for compassionate and competent care of the patient, and Inger Holmström for excellent typing of the manuscript. This study was supported by grants from the Swedish Cancer Society (CAN2011/419), the Swedish Research Council (K2011-64X-05971-31-6 and K2012-99X-22013-01-3), the Childrens' Cancer Foundation (PROJ09/093 and PR2013-0020), the Cancer Society in Stockholm (111293 and 121092), and Karolinska Institutet.

\section{Conflict of Interest}

The authors indicate no potential conflict of interest. 
Citation: Ringdén O, Solders M, Erkers T, Nava S, Molldén P, et al. (2014) Successful Reversal of Acute Lung Injury using Placenta-Derived Decidual Stromal Cells. J Stem Cell Res Ther 4: 244. doi:10.4172/2157-7633.1000244

\section{References}

1. Rubenfeld GD, Caldwell E, Peabody E, Weaver J, Martin DP, et al. (2005) Incidence and outcomes of acute lung injury. N Engl J Med 353: 1685-1693. [PubMed]

2. Ashbaugh DG, Bigelow DB, Petty TL, Levine BE (1967) Acute respiratory distress in adults. Lancet 2: 319-323. [PubMed]

3. Matthay MA, Zemans RL (2011) The acute respiratory distress syndrome: pathogenesis and treatment. Annu Rev Pathol 6: 147-163. [PubMed]

4. Bernard GR, Artigas A, Brigham KL, Carlet J, Falke K, et al. (1994) The American-European Consensus Conference on ARDS. Definitions, mechanisms, relevant outcomes, and clinical trial coordination. Am J Respir Crit Care Med 149: 818-824. [PubMed]

5. Friedenstein AJ, Petrakova KV, Kurolesova AI, Frolova GP (1968) Heterotopic of bone marrow. Analysis of precursor cells for osteogenic and hematopoietic tissues. Transplantation 6: 230-247. [PubMed]

6. Haynesworth SE, Goshima J, Goldberg VM, Caplan Al (1992) Characterization of cells with osteogenic potential from human marrow. Bone 13: 81-88. [PubMed]

7. Le Blanc K, Rasmusson I, Sundberg B, Götherström C, Hassan, et al. (2004) Treatment of severe acute graft-versus-host disease with third party haploidentical mesenchymal stem cells. Lancet 363: 1439-1441. [PubMed]

8. Ringden O, Uzunel M, Rasmusson I, Remberger M, Sundberg B, et al. (2006) Mesenchymal stem cells for treatment of therapy-resistant graft-versus-host disease. Transplantation 81: 1390-1397. [PubMed]

9. Remberger M, Ringden O (2012) Treatment of severe acute graft-versus-hos disease with mesenchymal stromal cells: a comparison with non-MSC treated patients. Int J Hematol 96: 822-824. [PubMed]

10. Trowsdale J, Betz AG (2006) Mother's little helpers: mechanisms of maternalfetal tolerance. Nat Immunol 7: 241-246. [PubMed]

11. Karlsson H, Erkers T, Nava S, Ruhm S, Westgren M, et al. (2012) Stromal cells from term fetal membrane are highly suppressive in allogeneic settings in vitro. Clin Exp Immunol 167: 543-555. [PubMed]

12. Ringden O, Erkers T, Nava S, Uzunel M, Iwarsson E, et al. (2013) Fetal membrane cells for treatment of steroid-refractory acute graft-versus-hos disease. Stem Cells 31: 592-601. [PubMed]

13. Aslam M, Baveja R, Liang OD, Fernandez-Gonzalez A, Lee C, et al. (2009) Bone marrow stromal cells attenuate lung injury in a murine model of neonatal chronic lung disease. Am J Respir Crit Care Med 180: 1122-1130. [PubMed]

14. Gupta N, Su X, Popov B, Lee JW, Serikov V, et al. (2007) Intrapulmonary delivery of bone marrow-derived mesenchymal stem cells improves survival and attenuates endotoxin-induced acute lung injury in mice. J Immunol 179: 1855-1863. [PubMed]

15. Lee JW, Fang X, Gupta N, Serikov V, Matthay MA (2009) Allogeneic human mesenchymal stem cells for treatment of $E$. coli endotoxin-induced acute lung injury in the ex vivo perfused human lung. Proc Natl Acad Sci USA 106: $16357-$ 16362. [PubMed]

16. Nemeth K, Leelahavanichkul A, Yuen PS, Mayer B, Parmelee A, et al. (2009) Bone marrow stromal cells attenuate sepsis via prostaglandin $\mathrm{E}(2)$-dependent reprogramming of host macrophages to increase their interleukin-10 production. Nat Med 15: 42-49. [PubMed]
17. Hayes C, Lush RJ, Cornish JM, Foot AM, Henderson J, et al. (1998) The outcome of children requiring admission to an intensive care unit following bone marrow transplantation. Br J Haematol 102: 666-670. [PubMed]

18. Ringden O, Ruutu T, Remberger M, Nikoskelainen J, Volin L, et al. (1994) A randomized trial comparing busulfan with total body irradiation as conditioning in allogeneic marrow transplant recipients with leukemia: a report from the Nordic Bone Marrow Transplantation Group. Blood 83: 2723-2730. [PubMed]

19. Ringden $O$, Remberger M, Persson U, Ljungman $P$, Aldener A, et al. (1995) Similar incidence of graft-versus-host disease using HLA-A, -B and -DR identical unrelated bone marrow donors as with HLA-identical siblings. Bone Marrow Transplant 15: 619-625. [PubMed]

20. Storb R, Deeg HJ, Pepe M, Appelbaum F, Anasetti C, et al. (1989) Methotrexate and cyclosporine versus cyclosporine alone for prophylaxis of graft-versus-host disease in patients given HLA-identical marrow grafts for leukemia: long-term follow-up of a controlled trial. Blood 73: 1729-1734. [PubMed]

21. Erkers T, Nava S, Yosef J, Ringdén O, Kaipe H (2013) Decidual stroma cells promote regulatory $T$ cells and suppress alloreactivity in a cell contactdependent manner. Stem Cells Dev 22: 2596-2605. [PubMed]

22. Moodley Y, llancheran S, Samuel C, Vaghjiani V, Atienza D, et al. (2010) Human amnion epithelial cell transplantation abrogates lung fibrosis and augments repair. Am J Respir Crit Care Med 182: 643-651. [PubMed]

23. Martin GS, Mangialardi RJ, Wheeler AP, Dupont WD, Morris JA, et al. (2002) Albumin and furosemide therapy in hypoproteinemic patients with acute lung injury. Critical Care Medicine 30: 2175-2182. [PubMed]

24. Gao J, Dennis JE, Muzic RF, Lundberg M, Caplan Al (2001) The dynamic in vivo distribution of bone marrow-derived mesenchymal stem cells after infusion. Cells Tissues Organs 169: 12-20. [PubMed]

25. Ringden O, Uzunel M, Sundberg B, Lönnies L, Nava S, et al. (2007) Tissue repair using allogeneic mesenchymal stem cells for hemorrhagic cystitis, pneumomediastinum and perforated colon. Leukemia 21: 2271-2276. [PubMed]

26. (2013) Mesenchymal Stem Cell Therapy. Humana Press, Springer Verlag, London.

27. (2014) Stem Cell Dependent Therapies. Mesenchymal Stem Cells and Chronic Inflammatory Disorders. De Gruyter, Berlin.

28. Jung JW, Kwon M, Choi JC, Shin JW, Park IW, et al. (2013) Familial occurrence of pulmonary embolism after intravenous, adipose tissue-derived stem cell therapy. Yonsei Med J 54: 1293-1296. [PubMed]

29. Weiss DJ (2014) Concise review: current status of stem cells and regenerative medicine in lung biology and diseases. Stem Cells 32: 16-25. [PubMed]

30. Zheng G, Huang L, Tong H, Shu Q, Hu Y, et al. (2014) Treatment of acute respiratory distress syndrome with allogeneic adipose-derived mesenchyma stem cells: a randomized, placebo-controlled pilot study. Respir Res 15: 39. [PubMed]

31. Weiss DJ, Casaburi R, Flannery R, LeRoux-Williams M, Tashkin DP (2013) A placebo-controlled, randomized trial of mesenchymal stem cells in COPD Chest 143: 1590-1598. [PubMed] 